found up to the time of flowering and, although it is admitted that the absence of such a drift with time is not proved, Heath claims that his data confirm the findings of Gregory ${ }^{5}$. The latter found the net assimilation rate (area basis) to be independent of time up to maximum leaf area in barley, and he accounts for 80 per cent of the variation of his data in terms of the variation in external factors.

In our own experiments with Sudan grass and oats $^{3,4}$, there are marked significant falls with time in the net assimilation rate or unit leaf rate (dry weight basis) before flowering. With the tobacco plant, too, unpublished data from this laboratory show very rapid falls in net assimilation rates with time on either dry weight or area bases. That the falls are not solely due to an effect of temperature is clear from the fact that the oats ${ }^{4}$ were grown under conditions of steadily rising mean daily maximum temperatures. With the Sudan grass ${ }^{3}$ also, temperature was rising during a portion of the period before flowering.

Where the dry weight basis is used, a progressive increase in the fibre content of the leaves would partly account for a fall in the net assimilation rate with age; this points to the inadequacy of the dry weight basis for comparative measurements. It is also possible that the use of leaf area as a basis for the expression of metabolic rates introduces time drifts of a complicated kind.

The data from this laboratory call for further interpretation, and to this end analytical work is already in progress.

Waite Agricultural Research Institute,

R. F. WILLIAMS. University of Adelaide. Nov. 8.

${ }^{1}$ Heath, O. V. S., Ann. Bot., N.S. 1, 565 (1937).

${ }^{2}$ Heath, O. V. S., J. Agric. Sci. (in press).

${ }^{3}$ Ballard, L. A. T., and Petrie, A. H. K., Austral. J. Exp. Biol. 14, 135 (1936).

Williams, R. F., Austral. J. Exp. Biol., 14, 165 (1936).

'Gregory, F. G., Ann. Bot., 40, 1 (1926).

\section{Series Effect on the Dipole Moments of Some Alkyl} Halides

THE problem of induction along hydrocarbon chains has been the subject of some of our previous papers ${ }^{1}$ on measurements of dipole moments in solution. The experiments now reported relate to the moments of alkyl bromides and iodides as determined in benzene solution at $20^{\circ}$, and the values may be compared with those determined with the vapours ${ }^{2}$.

Although earlier values of these moments determined in solution have been published ${ }^{3}$, considerable divergencies exist among the results, and neither of the two series has been completely investigated in solution under the same conditions. The apparatus and the method of calculation used were those previously described ${ }^{4}$. The values of the polarizations and the dipole moments, expressed in Debye units, are given below.

\begin{tabular}{|c|c|c|c|}
\hline Compound & $P_{2 \infty}$ (c.c.) & $P E$ (c.c.) & $\mu$ \\
\hline $\mathrm{CH}_{3} \mathrm{I}$ & $61 \cdot 5$ & $19 \cdot 3$ & $1 \cdot 41$ \\
\hline $\mathrm{C}_{2} \mathrm{H}_{5} \mathrm{I}$ & $90 \cdot 8$ & $24 \cdot 2$ & $1 \cdot 78$ \\
\hline$n-\mathrm{C}_{8} \mathrm{H}_{7} \mathrm{I}$ & $101 \cdot 0$ & $28 \cdot 9$ & $1 \cdot 84$ \\
\hline$i-\mathrm{C}_{3} \mathrm{H}_{7} \mathrm{I}$ & $109 \cdot 5$ & $29 \cdot 3$ & $1 \cdot 95$ \\
\hline$n-\mathrm{C}_{4} \mathrm{H}_{8} \mathrm{I}$ & $105 \cdot 0$ & $33 \cdot 5$ & $1 \cdot 88$ \\
\hline$n-\mathrm{C}_{5} \mathrm{H}_{11} \mathrm{I}$ & $109 \cdot 7$ & $38 \cdot 2$ & $1 \cdot 88$ \\
\hline $\mathrm{C}_{2} \mathrm{H}_{5} \mathrm{Br}$ & $94 \cdot 9$ & $19 \cdot 1$ & $1 \cdot 89\left(^{5}\right)$ \\
\hline$n-\mathrm{C}_{8} \mathrm{H}_{7} \mathrm{Br}$ & $102 \cdot 8$ & $23 \cdot 6$ & 1.93 \\
\hline$i \cdot \mathrm{C}_{8} \mathrm{H}_{7} \mathrm{Br}$ & $112 \cdot 2$ & $23 \cdot 9$ & $2 \cdot 04$ \\
\hline$n-\mathrm{C}_{4} \mathrm{H}_{9} \mathrm{Br}$ & $107 \cdot 4$ & $28 \cdot 3$ & 1.93 \\
\hline$n-\mathrm{C}_{3} \mathrm{H}_{11} \mathrm{Br}$ & $113 \cdot 7$ & $33 \cdot 0$ & 1.95 \\
\hline
\end{tabular}

The difference between the bromides and iodides is striking. The moments of the $n$-iodides increase as far as the butyl compound and then preserve a constant value, while those of the $n$-bromides show no increase beyond $n$-propyl bromide. Although the moments of the iodides are slightly lower than those of the corresponding bromides, the increase thus extends over a further carbon atom in the former. Both the $i$-propyl compounds possess larger moments than their isomeric $n$-compounds.

The increases in moment with extension of the carbon chain shown by the vapours are larger and apparently continue to higher members of the series. The measurements in solution are complicated by the effect of the principal dipole upon the surrounding solvent molecules, as well as by its influence upon other parts of the polar molecule. For compounds of the present type, the first effect should give rise to an induced moment which opposes the principal dipole of the molecule ${ }^{6,7}$, whereas the moment induced in the second case should either increase or decrease the total moment according as additional polarizable matter is brought within or outside two cones of semi-angle $55^{\circ}$ about the dipole axis ${ }^{6}$. Lengthening of the hydrocarbon chain would to some extent add $\mathrm{CH}_{2}$ groups in this space, and the percentage increase in moment in homologous series should be uniform. That this conclusion is not confirmed by experiment is probably due to the necessary approximations in the theory.

The contributions to the resultant moment of the molecule of the moments induced by the primary dipole in the parts without and within the cones would differ with the polarizability and size of the halogen atom, and the secondary effects produced by addition of $\mathrm{CH}_{2}$ groups would probably vary in the two cases. The polarizability and size of the iodine atom exceed those of the bromine atom, and it is in the iodides that the greater inductive effect is shown.

It seems that the polarizability of the polar group is a more important factor than the magnitude of the principal dipole in determining the change of moment in these series. This is also shown by the fact that the polarizability of the nitrile group is smaller than that of the iodo-group and, although it possesses a greater moment, the percentage varia. tion of the moment in the nitriles is smaller and the moment attains its limit more quickly than in the iodides.

A fuller account of these results will shortly be published.

Queen Mary College,

E. G. COWLey.

J. R. Partington.

University of London. Nov. 23.

Cowley and Partington, J. Chem. Soc., 1252 (1933); 604 (1935).

${ }^{2}$ Groves and Sugden, J. Chem. Soc., 158 (1937).

${ }^{3}$ See Trans. Faraday Soc., 30, Appendix p. 21 (1934).

${ }^{4}$ Cowley and Partington, J. Chem. Soc., 1184 (1936).

${ }^{5}$ Cowley and Partington, J. Chem. Soc., 130 (1937).

${ }^{6}$ Frank, Proc. Roy. Soc., A, 152, 171 (1935).

7 Higasi, Sci. Papers Inst. Phys. Chem. Res., Tokyo, 28, 284 (1936).

Potato Flowers and Dissemination of Potato Viruses

THE exact method of the spread of virus $X$ in the field is not yet known. It has been suggested, however, that a species of thrips is the vector and that infection is conveyed by the insect feeding in the flowers ${ }^{1}$. 